\title{
AS MUSICALIDADES DAS RODAS DE CAPOEIRA: INVESTIGAÇÃO DE UM CAMPO DE SABER/PODER(?)*
}

\author{
Márcio Penna Corte Real \\ Universidade Federal de Goiás, Goiânia, GO, Brasil
}

\begin{abstract}
Resumo: Neste texto, discutem-se os papéis das musicalidades da capoeira. Recorre-se à noção de campo na análise da contradição entre o potencial educativo intercultural das musicalidades na/ da capoeira e a possibilidade de constituírem-se em objetos de disputas entre seus agentes. Destaca-se como fio condutor do enredo argumentativo a ideia de rodas de capoeira, como alegoria para o método expositivo. Tomam-se como dados aspectos das histórias de mestres de capoeira que viveram em Salvador, BA, entre 1890 e 1994; e entrevistas realizadas durante três meses de trabalho de campo, nesta cidade. O trabalho resultou em contribuições concernentes à investigação de processos de ensino-aprendizagem das musicalidades e à constituição de saberes de educadores em espaços não formais, entendidos como campos de saber e de poder.

Palavras-chave: Capoeira. Musicalidades. Campo. Educadores.
\end{abstract}

\author{
Senhores, peço licença \\ Senhores, peço licença, ô meu bem \\ Para cantar uma história, \\ O Valente Vilela, ô meu bem \\ Trago sempre na memória \\ Ele lutou quinze anos \\ Fez a canção da vitória \\ Mestre Waldemar da Paixão
}

* Artigo recebido em 4/11/2013 e aprovado em 24/1/2014. 


\section{CANTO de ENTRADA: INTRODUÇão}

A epígrafe acima faz alusão ao canto de entrada típico das rodas de capoeira, conhecido como ladainha - canto narrativo de múltiplas influências, desde europeias e africanas, até sagradas e profanas. Sua intencionalidade e forma se assemelham a uma oração, em que um solista executa o canto de lamento, evocando diferentes temas, como feitos de capoeiristas, situações de desafio etc. Ao final da narrativa, é executada a louvação, na qual o solista executa versos, que são repetidos pelo coro, formado pelos integrantes da roda de capoeira.

Neste trabalho, tematizo os papéis exercidos pelas músicas da capoeira(s), entre eles os aspectos de sua dimensão educativa. Por um lado, abordo estratégias de ensino que os seus agentes desenvolvem; as visões e os significados, que atribuem a estes saberes - aqui chamados de musicalidades. Por outro, discuto a possibilidade de constituírem estas musicalidades objetos de prestígio e de disputa por posições de destaque neste espaço singular, que é o universo cultural da capoeira.

Este cenário investigativo tange às questões da educação musical, no que diz respeito aos processos não formais de ensino e aprendizagem da música; e da educação, em sentido mais amplo, no tocante aos processos de formação e atuação de educadores no âmbito das práticas culturais. ${ }^{2}$ As musicalidades são saberes constitutivos da organização e desenvolvimento das rodas de capoeira, bem como das práticas de seus educadores. Assim, abarcam: cantos e instrumentos musicais, letras de músicas, formas de confeccionar instrumentos, e as maneiras de organizá-los nas rodas de capoeira. A ideia de musicalidades tem o intuito de expressar as estratégias de dinamização destes saberes, as visões e os significados que Ihes são atribuídos pelos(as) capoeiristas.

A roda consiste no encontro, no espaço e no tempo simbólico no qual os capoeiristas se reúnem para um ritual que envolve dimensões de dança, arte e música, como aspectos de luta entre dois jogadores, então, oponentes, animados por cânticos alusivos à memória dos negros. Assim, expressam dimensões de lutas coletivas, de resistência cultural e de contestação social. A observação de Landes (2002, p. 19), ao final dos anos de 1930, em Salvador, dá uma imagem da roda de capoeira:

Chegáramos ao lugar onde os homens se preparavam para a capoeira. Os espectadores se apinhavam à volta de um largo círculo e não havia nem mulher nem sacerdote entre eles. Num ponto do interior do círculo estavam três negros altos, cada qual segurando um berimbau, com uma das extremi- 
dades apoiada no chão. Logo surgiram outros instrumentistas - um com um chocalho, outro com um pandeiro. [...] Dois capoeiras estavam agachados diante dos músicos. Um era o campeão Querido-de-Deus, cujo nome de batismo era Samuel. Era alto, mulato, de meia-idade, musculoso, pescador de profissão. O seu adversário era Onça Preta, mais moço, mais baixo, mais gordo. Estavam ambos descalços, usavam camisas-de-meia listadas, um de calças brancas, outro de calças escuras, um de chapéu de feltro, outro com um boné que depois trocou por um palheta. Agachados, de chapéu e descalços, tinham um dos braços apoiado nas coxas e olhavam diretamente para a frente, descansando. Eram obrigados a guardar silêncio e a obrigação estendia-se à assistência. A orquestra deu início à diversão, numa desafinada invocação; e esse fundo musical monótono, também, era essencial à ocasião. Era uma espécie de lamentosa tessitura anasalada, dentro da qual os homens realizavam maravilhas acrobáticas, sempre dentro da batida correta, enquanto os instrumentistas cantavam versos zombeteiros: Era uma canção de desafio, esperança e resignação, com fragmentos de ideias de rebeldia. Não possuía um tema único, bem trabalhado, mas resumia um tipo de vida e de protesto. E fazia começar a luta. Querido-de-Deus balançava os quadris enquanto encarava o adversário, mostrando-lhe os dentes, e avaliava as suas possibilidades. A luta envolvia todas as partes do corpo, exceto as mãos, precaução exigida pela polícia para evitar danos. À medida que os movimentos se amoldavam à música, eles se movimentavam numa sequência lenta, como de sonho, que mais parecia uma dança do que uma luta. [...]. Havia vários tipos de capoeira, com sutilezas na forma e na sequência dos golpes e no modo de tocar os berimbaus.

Ao longo deste texto, tomo como referência a representação das rodas de capoeira, como alegoria para caracterizar cada espaço-tempo, que serve como foco para as análises realizadas. Inicialmente a ideia de rodas de capoeira faz alusão ao espaço temporal da cidade de Salvador, BA, entre 1890 e 1994. Então, focalizo aspectos da história dos personagens da capoeira: Mestre Bimba, Mestre Canjiquinha, Mestre Pastinha e Mestre Waldemar, por terem marcado fortemente este universo cultural, no que diz respeito às características de suas musicalidades. A história é reivindicada como a forma para a compreensão do desenvolvimento deste campo de saber e de poder.

Neste prisma, uma obra cultural, como a música, tem significados e valores distintos, de acordo com seu autor (BouRdieu, 1996; 2000; 2003). A obra carrega um valor, definido pelo nível de reconhecimento do autor. A noção de campo procura entender as regras, explícitas ou veladas, que fazem com que agentes de um mesmo espaço de produção cultural se diferenciem entre si, em termos de posições de poder. 
Na continuidade, convido outros jogadores a formar a segunda roda de análises, tendo como espaço-tempo a cidade da Bahia contemporaneamente. Esta roda é formada por jogos de visões e significados expressos por nove mestres de capoeira e um pesquisador autodidata, entrevistados de 6 de janeiro a 6 de abril de $2005 .{ }^{3} \mathrm{Na}$ perspectiva de compreender a capoeira como um campo de saber e de poder, os dados advindos das entrevistas permitem a trama de diálogos interculturais (ANDREOLA, 2000; FreIRE, 1987) em torno das práticas educativas musicais deste espaço.

À guisa de considerações finais ou de canto de despedida, como diriam os capoeiristas, dou ênfase a aspectos que permitem fazer inferências sobre as dimensões educativas das musicalidades das rodas de capoeira(s), ao mesmo tempo que apontam para a imanência da constituição de um campo de saber e de poder.

\section{A CIDADE DA BAHIA DE 1890-1994: A EMERGÊNCIA DAS MUSICALIDADES}

Analisar as influências da capoeira da Bahia na constituição do campo cultural da capoeira, no qual as musicalidades são características determinantes, permite traçar uma linha de investigação que tem como cenário a cidade de Salvador, ao final do século XIX. Possivelmente outras raízes culturais exerceram influências no que se refere às musicalidades da capoeira. Todavia, a Bahia parece ser um ponto de partida fundamental, vistas suas contribuições e por ser o espaço de formação e atuação de alguns mestres que influenciaram estas práticas de musicalidades.

A configuração do espaço-tempo desta primeira roda tem como referência o ano de 1890. A partir deste ano nasceram os agentes da capoeira aqui analisados: Mestre Bimba; Mestre Canjiquinha; Mestre Pastinha; e Mestre Waldemar da Paixão. O palco é a cidade de Salvador, também conhecida como Cidade da Bahia de Todos os Santos. O código penal de 1890 começava a ter repercussão no Rio de Janeiro de então, no que diz respeito à perseguição, prisão e repressão aos capoeiras, que se intensificavam. No contexto da Bahia, do século XIX, a capoeira fazia parte de um conjunto de manifestações culturais afro-brasileiras, que eram reprimidas, como as músicas e a religiões afro-brasileiras (PIRES, 2004; ABIB, 2004). E este período histórico torna-se significativo para o estudo da capoeira, no que diz respeito às suas musicalidades.

O primeiro personagem a adentrar nesta roda é Mestre Bimba. Tendo iniciado no mundo da capoeira aos 12 (doze) anos de idade, um certo africano Nozinho Bento, o Bentinho, Capitão da Companhia Baiana de Navegação, ficou conhecido como quem Ihe ensinou capoeira, na Estrada das Boiadas, 
hoje Bairro da Liberdade, em Salvador (UCSAL, 2003; REGO, 1968; VIEIRA, 1995). Mestre Bimba era o $25^{\circ}$ (vigésimo quinto) filho de Maria Martinha do Bonfim, descendente de índios tupinambás e de Luiz Cândido Machado, um exescravo banto (UCSAL, 2003).

Este personagem, chamado Mestre Bimba, que ficaria conhecido pela criação da Capoeira Regional, nasceu em 23 de novembro de 1899, em Salvador (FALCÃO, 2004; UCSAL, 2003). Outra data é atribuída a seu nascimento (ReIS, 1997; VIEIRA, 1995; REGO, 1968); e de acordo com a Revista Memórias da Bahia (UCSAL, 2003, p. 14):

"Os negros cantam suas lutas misteriosas." Este é o título da reportagem em que o procurador judicial Ramagem Badaró descreve maravilhado a luta, na revista Saga de agosto de 1944. Na matéria, Bimba aparece identificado como "O grande rei negro do misterioso rito africano." Um reconhecimento que, pouco a pouco, se alastrava pelas ruas e becos da província da Bahia, mas que começara anos antes, em 23 de novembro de 1899 (ele tinha outra certidão em que constava 1900), no Engenho Velho de Brotas, pouco mais de uma década após a abolição da escravatura.

Mestre Bimba foi considerado o primeiro disciplinador e pedagogo da capoeira. Desenvolveu uma nova modalidade, que chamou Capoeira Regional, justificando esta escolha "porque a capoeira nasceu aqui na Bahia, em Cachoeira, Santo Amaro e llha de Maré" (Diário de Notícias apud REIS, 1997, p. 129). A criação da Capoeira Regional acarretou, entre outras consequências, o emprego de uma visão e prática de musicalidade. A não utilização do atabaque, por exemplo, foi uma das diferenciações de Mestre Bimba em relação à capoeira tradicional, chamada de Angola.

Reis $(1997$, p. 133) comenta a ausência do atabaque na Capoeira Regional:

Conta-se que Mestre Bimba, durante as décadas de 30 e 40, teria retirado o atabaque das rodas para tentar desvincular a capoeira do candomblé. Tal atitude do mestre é exemplar no que respeita à ambiguidade de sua conduta, à qual já me referi antes, podendo ser interpretada como uma estratégia para evitar a repressão, sem significar uma desqualificação desse culto afro-brasileiro do qual, inclusive, Bimba participava como ogã (cargo masculino responsável pelos atabaques) num terreiro de candomblé Angola pertencente a uma de suas mulheres, que era mãe-de-santo. Em seu disco, gravado na década de 60 , o atabaque faz parte da orquestra musical da capoeira, lado a lado com berimbau e o pandeiro, e o coro traz vozes femininas diversas, resultando num timbre de qualidade vocal comparável aos responsórios do candomblé e de outras manifestações culturais negras. 
$\mathrm{O}$ atabaque aparece na literatura como instrumento musical com designação de tambor oblongo, isto é, com couro em apenas um dos lados do cilindro que forma sua estrutura. A palavra tablak, base da origem de sua nomenclatura, é de origem persa, comum na Ásia e na África. É possível que o atabaque tenha sido introduzido no Brasil pelos negros (AlvarenGA, 1950, p. 303).

Em relação ainda ao aspecto musical da Capoeira Regional, Mestre Bimba organizou toques de berimbau (espécie de padrões rítmicos) e estabeleceu, através deles, uma hierarquia entre alunos formados e não formados. Isto porque,

[...] Mestre Bimba empreende também a sistematização dos toques de berimbau (considerado como o principal instrumento musical da capoeira), criando uma metodologia para seu ensino. Em seu disco Curso de Capoeira Regional o Mestre, exímio tocador de berimbau, gravou em um dos lados os sete toques da Regional: São Bento Grande, Cavalaria, Benguela, Santa Maria, lúna, Idalina e Amazonas. (REIS, 1997, p. 137)

Mestre Bimba gozou de prestígio não só pela criação da capoeira Regional e por ser reconhecido como grande lutador, mas por ser considerado bom tocador de berimbau (UCSAL, 2003; REGO, 1968). Os principais aspectos das musicalidades empregados na capoeira Regional, como a organização do conjunto musical com um berimbau e sem a presença do tambor, chamado de atabaque, ainda hoje são seguidos pelos capoeiristas vinculados a esta escola.

Outro personagem da capoeira em destaque no período e que adentra nesta roda de discussão é Washington Bruno da Silva. Mestre Canjiquinha, como era conhecido, nasceu em 1925, em Salvador, filho de um alfaiate, chamado José Bruno da Silva, e de uma costureira, chamada Amália Maria da Conceição. Em vida, foi um dos capoeiristas mais admirados da Bahia. E chegou a falar sobre a fama e a distinção, que vinha obtendo - em entrevistas reunidas em livro:"uma vez, eu tava em S. Paulo, 1962, na Feira de Arte Popular. Então, eu fui num teatro vestido de camisa. Aí, o cara na porta barrou e o rapaz que me acompanhava disse: - Esse é o mestre Canjiquinha. Então, as portas se abriram só por causa do meu nome" (MESTRE CANIIQUINHA, s.d., p. 16).

Entre suas realizações, no âmbito das musicalidades da capoeira, está a criação de toques de berimbau, sobre os quais afirmou:

Se o mestre Bimba criou a regional eu achei por bem criar a muzenza, o samango. Se toca diferente, se joga diferente. Isso passou na minha cabeça assim: é muzenza, é muzenza. Toquei no berimbau. Aí eu disse: como é que eu vou jogar isso? Aí eu botava o Manuel, o finado Simpatia, Gerônimo treinando os movimentos. Vi que aquilo prestava. É muzenza. (p. 40) 
Mestre Canjiquinha exerceu várias atividades, com a preocupação de ajudar sua mãe, até se tornar funcionário público, em 1942, ajudado por um homem de nome Marcelino, que o colocou como ajudante de serviços gerais na prefeitura de Salvador (s.d. p. 46). Este trabalho foi determinante, pois Ihe possibilitou a divulgação da capoeira, por meio da realização de shows folclóricos, em espaços voltados ao turismo.

Este personagem da capoeira deu sinais de compreender o significado de fazer parte de um meio estratificado, em que os indivíduos ocupam posições de maior ou menor destaque em relação uns aos outros:

Com sinceridade eu nunca tive rixa com nenhum capoeirista. Só com o meu amigo Caiçara de vez em quando. Eu sempre me dei bem com o mestre Pastinha, com o mestre Bimba, com Valdemar, com Cobrinha Verde. Eu sempre me dei bem, porque eu tinha que ser inteligente. Porque era eu quem precisava deles. Porque eles eram mais velhos. Então, eu não ia brigar com esses homens. (s.d., p. 42; grifos meus)

Isso revela a habilidade, por parte de Mestre Canjiquinha, para lidar com o fato de "precisar" e de reconhecer as posições ocupadas por outros capoeiristas, "os mais velhos". Este mestre foi um dos capoeiristas que mais obteve destaque e reconhecimento no campo da capoeira, através de inovações que fez, ao introduzir práticas culturais neste universo, tais como, samba de roda, maculelê e puxada de rede.

O seu contato com o samba de roda se deu por meio de sua mãe e sua tia, que participavam da dança (SHAFFER, 1977). O samba de roda consiste numa dança, realizada em círculo. Seu acompanhamento é feito por cantigas, na forma de pergunta e resposta, em que um solista canta e é acompanhado pelo coro, formado pelos integrantes da "brincadeira". O acompanhamento musical é formado por instrumentos de percussão: conjunto de três atabaques rum, rumpi e lê, e outros como agogô. "É a dança espontânea mais característica da Bahia. Dança de chão batido e céu aberto [...] é um gênero musicalcoreográfico, associado à dança da umbigada, no qual um elemento entra para o meio da roda [...], executa vários passos e vai dar uma umbigada na pessoa que escolher para substituí-lo" (BIANCARDI, 2000, p. 276).

Mestre Canjiquinha aprendeu a puxada de rede, quando menino: "A puxada de rede eu aprendi no tempo. Eu saía do Matatu e ia pra Boca do Rio, onde é o Jardim de Alá. [...] Eu ia com o finado Péricles. Ele ia montado no cavalo, eu na garupa. Lá eu via os caras cantando. Eu aprendi, puxando a rede original" (MeSTRE CANJIQUINHA, s.d., p. 51). A puxada de rede consiste em uma encenação, hoje, bastante comum nos batizados e apresentações de capoeira. Representa o arrastão feito pelos pescadores, que são movidos por 
cânticos e pela batida de atabaques, durante a pesca do peixe xaréu - peixe comum nas costas do nordeste brasileiro (FALCÃO, 2005, p. 1).

Ele teria aprendido maculelê em 1954, na ocasião em que Popó de Santo Amaro realizou uma apresentação, na Praça da Sé, na região do Centro Histórico de Salvador (SHAFFER, 1977, p. 38). As origens do maculelê não são precisas. Há indícios de que seja um auto popular de origem africana. É considerado uma brincadeira de negros, que se limitou às regiões do Recôncavo e vizinhas a Salvador (BIANCARDI, 1989, p. 7).

O maculelê é considerado uma dança de origem africana e um folguedo rural, sendo ignoradas a data e as condições da sua chegada ao Brasil. Herudino Leal o descreve como a dança antiga realizada pelos participantes saindo às ruas, dois a dois, em fila, formando um cortejo. E Paim descreve que os integrantes organizavam um círculo, divisado pelos atabaques (apud BIANCARDI, 1989, p. 19). Esta mesma autora declara que é

[...] da opinião de que o maculelê antigo, quando o grupo não estava andando, tinha a forma de círculo ou semi-círculo, passando, posteriormente, a constituir-se em duas alas, com o Mestre sozinho, ao meio, batendo as grimas de um lado e do outro, ou ficando apenas com uma ala, deixando a outra para o Contramestre. (p. 19)

Na parte musical, há relatos que incluem a presença de paralelepípedos ao lado de tambores, cânticos e melodias de candomblé e de outros folguedos que teriam sido adaptados por Mestre Popó. Destarte, Mestre Canjiquinha adverte, dizendo o seguinte:

Olha! Quem primeiro botou samba de roda na capoeira foi eu, na Rádio Sociedade com o finado Jota Luna e Milton Barbosa. Depois botei a puxada de rede na capoeira. Assim eu apresentava samba de roda e explicava. Depois apresentava a puxada de rede e explicava a história da puxada de rede. Depois o samba de caboclo e o maculelê. No final apresentava a capoeira, apresentando nome por nome dos golpes: martelo, ponteira, rabo de arraia, chapéu de couro... -, porque o público quer saber. Depois veio o Conjunto Aberrê Bahia. Dia de domingo, pegava meus alunos e ia apresentar. Mas, tudo isso, quem fez isso, quem introduziu todas essas coisas nos shows folclóricos foi seu criado. (Mestre CanjIQUinha, p. 33)

Rego (1968, p. 275) definiu Mestre Canjiquinha como capoeira jovem, que "canta como bem poucos e com um repertório vastíssimo, inclusive com uma grande facilidade de improvisar e de todos é quem mais tem contribuído para a adaptação de outros cânticos do folclore à capoeira." Suas contribuições para as musicalidades da capoeira incluem toques rítmicos para o seu principal instrumento musical, o berimbau, como muzenza e samango, 
além da inserção das danças do samba de roda, do maculelê e da puxada de rede no campo cultural da capoeira.

A seguir nesta roda de personagens da capoeira da Bahia dos finais do século XIX, tem lugar, no centro dos jogos, Vicente Ferreira Pastinha. Mestre Pastinha era um negro magro e pequeno, que nasceu na Bahia, a 5 de abril de 1899. Teve como pai um espanhol, chamado José Pastinha e, como mãe, uma negra de nome Raimunda dos Santos. Não criou - porque já era uma prática cultural corrente - mas ficou conhecido como o grande divulgador da chamada Capoeira Angola (ReIs, 1997; REGo, 1968). Este homem franzino, de fala mansa, começou a aprender capoeira na infância, pelos 8 ou 10 anos de idade, por piedade de um velho africano, chamado Benedito. Este senhor se compadeceu do então menino, que recebia uma surra cotidiana de outro menino maior e passou a ensinar-lhe algo de "mais valia" do que empinar pipas, a capoeira (Revista Realidade apud REIs, 1997, p. 139).

Em relação às musicalidades, parece inusitado - em referência à imagem dos dias atuais - Mestre Pastinha (1968, p. 35) ter dito que"o conjunto musical não é indispensável para a prática da Capoeira, mas é evidente que o 'jogo da Capoeira Angola' ao ritmo do conjunto típico que acompanha as melodias e improvisos dos cantadores adquire graça, ternura, encanto e misticismo que bole com a alma dos capoeiristas." Evidentemente, esta ideia está ligada àquilo que Mestre Pastinha entendia por "conjunto típico". Na prática existiram várias versões para o conjunto musical, sujeitas às possibilidades que os capoeiristas dispunham num determinado momento, à sua criatividade ou à sua compreensão sobre o emprego dos instrumentos musicais.

Para Mestre Pastinha, este conjunto tinha, além da função de graça, ternura, encanto e misticismo, "a finalidade de determinar o ritmo do 'jogo' que pode ser mais ou menos lento ou rápido". Os instrumentos que compõem tal conjunto, na Capoeira Angola de Mestre Pastinha, são berimbau, pandeiro, reco-reco, agogô, atabaque e chocalho. O berimbau era o instrumento que Mestre Pastinha considerava indispensável à roda, por ditar o andamento e o caráter do jogo da capoeira. Esta visão de musicalidade, expressa na disposição dos instrumentos do conjunto musical da Capoeira Angola (que difere da Capoeira Regional, principalmente pela utilização de três berimbaus e pela inclusão do atabaque), é, ainda hoje, usual nos capoeiristas vinculados a esta linhagem de capoeira.

Finalmente, tem destaque nesta roda de reflexões Mestre Waldemar da Paixão. Trata-se de uma das referências de destaque da música da capoeira, como ficou conhecida e praticada até os dias de hoje. Isto tanto no que diz respeito à maneira de cantar, envolvendo influências, como a literatura de 
cordel ${ }_{i}^{4}$ como na forma de tocar e de confeccionar o berimbau, no qual introduziu uma série mudanças.

$\mathrm{Na}$ abertura de CD gravado com Mestre Canjiquinha, Mestre Waldemar diz:

Me chamo Waldemar Rodrigues da Paixão. Nascido em 1916. Aprendi capoeira com Siri de Mangue, Canário Pardo, Tanabi de Piripiri. Levei quatro anos aprendendo. Em quarenta anos na Pero Vaz peguei a ensinar. E aí continuei ensinando. Agora parei de ensinar. Só faço fabricar meus berimbaus.

Mestre Waldemar relata a informalidade como se deu a aprendizagem junto a seus mestres:"Eles vinham para Piripiri, aquela roda danada. Foi quando eu peguei a aprender com ele. Eu era rapazinho. Comprava duzentos réis de vinho tinto, aquele copo branco de alça. Ele tomava e dizia:'Pronto. Vai aprender porque me deu vinho'. Era o pagamento" (ABREU, 2003).

Entre as contribuições no aprimoramento do berimbau figura o aprimoramento de sua corda:"Parece que originalmente, e até recentemente (1920-1930), a corda usada no berimbau era um material natural: um pedaço de cipó ou uma corda feita de lã" (SHAFFER, 1977, p. 22). Sobre o que o próprio mestre afirmou: "O arame era arame de cerca, não era arame de aço. Depois eles queimavam o pneu e tiravam aquele arame enferrujado, quebrava. Eu inventei abrir na raça pra sair cru" (ABREU, 2003).

A pintura do berimbau também é atribuída ao Mestre Waldemar, visto que Shaffer (1997, p. 26) afirma que: até 1940, os berimbaus eram da cor natural e muitas vezes até mesmo tinham casca; e diz não saber quem retirou a casca e os envernizou, mas comenta que Mestre Bimba fazia isso. Shaffer (1977, p. 27) diz ser "bem conhecido entre os Mestres que a primeira pessoa a pintar um berimbau foi Mestre Waldemar da Paixão". Em 1942, ao começar comercializar berimbaus, Mestre Waldemar teria criado uma pintura especial, adotada pela maioria dos mestres, com exceção a Mestre Bimba, que continuou usando apenas o verniz.

Seria preciso um texto à parte para investigar a trajetória do berimbau até a capoeira. Sumariamente, é possível verificar a presença de um instrumento denominado birimbao na Bahia, no século XVI: "O birimbao existiu na Bahia. D. Manuel de Menezes, cronista do século dezesseis, teve a oportunidade de fazer, talvez, a primeira referência até então à existência do brimbao na cidade de Salvador" (OLiveira, 1956, p. 233). A referência não diz respeito ao berimbau-de-barriga, utilizado na capoeira, mas, a um instrumento de ferro em formato de ferradura, executado com o auxílio da boca, usada como caixa de ressonância. Em determinados momentos, os nomes birimbao, brimbao e mesmo berimbau são utilizados para este 
instrumento que tem a boca como caixa de ressonância, enquanto o arco musical ou berimbau-de-barriga já recebeu nomes como urucungo. Vejamos as considerações de Alvarenga (1950, p. 312):

Urucungo, Orucungo, Oricungo, Uricungo, Ricungo, Rugungo (s.m.) - Instrumento de procedência africana que consiste num arco de madeira tendo um arame retesado passado entre pontas. Numa das extremidades, ou no centro do arame, é presa uma pequena cabaça de forma arredondada, com uma abertura circular. [...] Também chamado de Berimbau, Berimbau-de-barriga, Marimba, Gôbo, Bucumbumba, Gunga, Macungo, Matungo e Mutungo, e, em Belém do Pará, Marimba. Na Bahia, no jogo da capoeira, costuma associar-lhe o caxixi.

A autora conclui: "Urucungo ou Berimbau. Objeto n. 749. Arco de madeira, tendo um arame passado entre duas extremidades. Pendurada ao arco por uma corda, uma cabaça que funciona como caixa de ressonância" (Alvarenga, 1950, p. 315). É possível que a denominação berimbau, para designar o arco-musical da capoeira, tenha se generalizado paulatinamente, até tornar-se quase absolutamente exclusiva - sendo raras às vezes em que os(as) capoeiristas utilizam termos como gunga, marimba.

Ao retomar o protagonismo de Mestre Waldemar da Paixão destacamse contribuições para divulgação do berimbau e, através dele, da própria capoeira, que vão do aprimoramento da obtenção do arame, que serve como corda, à pintura, comercialização e divulgação do instrumento para além dos espaços da capoeira.

O período que vai de 1890 a 1994 consiste simbolicamente no espaço-tempo da primeira roda de capoeira objeto desta análise. A emergência das visões e práticas musicais dos mestres brevemente historiados deixaram marcas na forma como as musicalidades da capoeira vêm sendo organizadas e difundidas, conforme será visto em um conjunto de entrevistas realizadas com capoeiristas que foram seus discípulos.

\section{DIÁLOGOS INTERCULTURAIS}

A partir da ideia de diálogos interculturais busco explicitar as visões dos agentes da capoeira - mestres e um pesquisador da capoeira, num caso específico - sobre as musicalidades desta prática cultural. A categoria de diálogo intercultural tem como referência Andreola (2000), ao propor o diálogo intercultural como categoria para o dialogo entre as civilizações. A dialogicidade, como categoria político-pedagógica, tem expressão na obra de Freire (1987); e aqui procura denotar as lógicas, sentidos, usos e papéis 
que os capoeiristas atribuem às musicalidades da capoeira. Por vezes, suas visões podem coincidir, serem complementares ou mesmo destoantes, sem que se anulem.

Seguindo a ideia de esboçar diálogos interculturais, que valorizassem as opiniões dos entrevistados, os dados são expostos, primando, na medida do possível, por uma comunicação não violenta (BoURDIEU, 2001). Tal perspectiva considera as dificuldades que a realização de toda entrevista implica, visto que a presença física e simbólica de um entrevistador diante do entrevistado influencia as respostas dadas; por isso, toda "informação prévia permite improvisar continuamente as perguntas pertinentes, verdadeiras hipóteses que se apoiam numa representação intuitiva e provisória da fórmula geradora própria ao pesquisado para provocá-lo a se revelar mais completamente" (2001, p. 700; grifos meus).

As questões mais recorrentes visaram trazer à tona o entendimento dos entrevistados sobre: como os educadores de capoeira formulam e dinamizam seus saberes musicais - quais são as estratégias de ensino e aprendizagem para este fim; quais visões e significados têm em relação às musicalidades - que papéis Ihes atribuem. Além disso, foram feitas problematizações, que visavam analisar a possibilidade de as musicalidades exercerem relações de saber/poder da/na capoeira. Por isso, também lancei questões que poderiam esboçar pontos controversos em relação a diferentes opiniões dos agentes sobre as musicalidades. Essa dimensão esteve ligada à atuação dos Mestres historiados: Bimba, Canjiquinha, Pastinha e Waldemar da Paixão. A escolha dos entrevistados teve como critérios o fato de serem praticantes de capoeira Angola ou Regional; serem discípulos ou terem tido contato com os mestres de capoeira, que se destacaram no período de 1890 a 1994.

\section{PAPÉIS ATRIBUÍDOS ÀS MUSICALIDADES DAS RODAS DE CAPOEIRA}

Ao abrir esta roda de entrevistas, visando esboçar diálogos interculturais com os capoeiristas, na cidade da Bahia, na atualidade, a primeira questão problematizada foi a que diz respeito aos papéis atribuídos por esses agentes às musicalidades das rodas de capoeira. O primeiro interlocutor, que será chamado de Frede, um pesquisador autodidata da capoeira, vinculado ao Instituto Jair Moura, apresentou várias dimensões que caracterizam tal papel. Um primeiro aspecto para ele é que, na capoeira, assim como em outras "manifestações negras", a música é um forte elemento para o "desempenho das funções", indo além da animação. Isso é característica da capoeira que conhecemos: 
Eu acho que na capoeira é a mesma coisa, está entendendo, ela é fundamental. Aí as pessoas podem falar assim..., tem um argumento que a pessoa fala assim: "Ah, mas nem sempre a capoeira foi jogada com música". Quer dizer, eu não sei, mas nem toda a circunstância você usa a música, você joga a capoeira você precisa da música, não é. Eu posso aqui meter a mão em você e você usar dos recursos da capoeira e não tem música nenhuma. Mas essa capoeira que você aprendeu, ela é uma capoeira que você aprendeu com a música. (FREDE)

Outra dimensão destacada pelo entrevistado diz respeito ao aspecto narrativo e ao caráter histórico, presente em muitas músicas da capoeira. Ele definiu esta característica como "elo com o passado":

Então, a música vai fazendo você se lembrar, quer dizer, ela puxa toda essa questão que a gente fala hoje da ancestralidade, todas essas coisas, a música..., o quê que se faz quando você baixa no pé do berimbau, você chama por ela, não é, você vai fazer as suas saudações. Então, ela tem um lado desse elemento de ser uma fala, uma fala do passado, uma fala da história da capoeira, quer dizer, é por onde transpira a poesia da capoeira. (FreDE)

É oportuno sublinhar que os jogadores atribuem múltiplos papéis às musicalidades. Por exemplo, o interlocutor, chamado de Mestre Cafuné, define esse papel, tocando em conceitos musicais e na interação entre as consciências. Este mestre, ligado à Capoeira Regional e à Fundação Mestre Bimba, em Salvador, disse:

Eu acho que a música..., quando eu ouço a música dos antigos, principalmente, na capoeira, eu sinto que a melodia, a cadência, o ritmo, o som das palavras, as palavras em si, as letras, né, e o som dessas palavras, que eram colocadas, ela tem toda uma função dentro da capoeira de fazer com que haja um trabalho de nível de consciência de quem está participando, não só de quem está jogando, mas quem está tocando, quem está batendo palma, para fazer uma ligação, para fazer uma corrente, em que as consciências [...]. ["Com o grupo?"] Com o grupo. Em que as consciências trabalhem dentro do mesmo nível de consciência. Até brincando, até que ponto a gente pode dizer que isso é brincadeira, eu digo sempre até no momento em que baixa a entidade capoeira em todo mundo [risos]. (Mestre CAFuné)

A música é vista como tendo uma função agregadora dos participantes do ritual da roda de capoeira, agindo no nível das consciências, como o mestre disse. É possível, portanto, que as musicalidades exerçam importante papel de comunicação, dando forte sentido de grupo aos participantes.

Próxima a essa dimensão de comunicação, outro jogador desta roda, que chamaremos Mestre Moa do Catendê, praticante de Capoeira Angola, 
e membro da Associação Brasileira de Capoeira Angola ( $A B C A$ ), também na cidade da Bahia, entende o papel das musicalidades como sendo ligado ao favorecimento de uma comunhão entre os seres humanos e o universo.

A música na capoeira é a ritmia, né cara, é a comunhão entre o capoeira, o capoeirista com o cosmo, né. Então a capoeira, a música, ela é a própria alma..., o berimbau é a própria alma da capoeira, né. Sem o ritmo, sem o toque e sem os fundamentos não existe capoeira, né. Aí vira uma luta marcial, como eles..., vira qualquer coisa, né. Então essa arte da musicalidade da capoeira ela, além de traduzir para o capoeirista essa alma, ela traduz para o mundo a importância da resistência do negro, né velho. (MESTRE MoA do CATENDÊ)

Há, ainda, a compreensão das musicalidades como canal de conexão entre o sensível e o intangível. O que sugere a ideia de que a arte esteja ligada ao que é mágico e incompreensível, servindo para justificar sua presença em importantes momentos da vida humana. Esta esfera, ligada à transcendência, foi destacada pelo jogador de capoeira, Mestre China, responsável pelo grupo de Capoeira Angola Barcelona, na Espanha:

Para mim a musicalidade na capoeira é a coisa mais importante, é o veículo aonde mexe com o ser humano, com o lado, com o ser, como posso dizer para você entender, o sobrenatural e o natural. Então, a música da capoeira não é para qualquer um, a pessoa tem que ter sentimento para transmiti-la. E eu acho que nesse momento havia muito sentimento e muita sinceridade, por isso que saiu o que vocês ouviram. (Mestre CHINA)

A diversidade de papéis atribuídos às musicalidades mostra uma das faces mais ricas da capoeira, qual seja, a possibilidade de diferentes sentidos e compreensões destes saberes, as quais, longe de residirem no campo do certo ou do errado, demonstram, em parte, como esses agentes significam seus saberes.

Mestre Neco, outro angoleiro da ABCA afirma: "A música dá mais harmonia, dá mais alegria, o cara solta mais o jogo, porque se você fizer uma bateria, e não estiver tocando direito, o jogo não sai bonito, o jogo não sai bom." Nesse sentido, a música é um elemento que também colabora para o desempenho dos capoeiristas na roda, para o "jogo bonito." De maneira semelhante, Mestre Raimundo se manifestou, falando sobre a função de animação das musicalidades. Este jogador de capoeira, membro da ABCA e ligado ao grupo de capoeira Globo Brasil em Salvador, assim opinou:

Olha, a função da música dentro da capoeira, especificamente na Angola, é uma animação, né, que dá para o capoeirista, porque a capoeira ela veio baseado no samba, a capoeira baseou na vadiagem, defesa, luta e para haver 
uma tapeação, né, na hora que o senhor de engenho percebesse que estavam, os negros, reunidos vadiando, a capoeira aí desmanchava em samba, né. E essa experiência foi aprovada, aí botaram a música na capoeira, né, para disfarçar e esse disfarce está até hoje, né, e todo mundo gosta, talvez a música dentro da capoeira é um objetivo para atrair muitas pessoas para a capoeira.

Além disso, o Mestre Raimundo concluiu: "Ela proporciona muita alegria, muito axé, porque música, né, música é uma coisa que quem canta é porque está alegre, né." A alegria faz com que a capoeira seja vista, pelo mestre, em um contexto alegre que congrega os capoeiristas, como se fossem uma família.

Outro jogador, o Mestre Cobrinha, da Fundação Internacional de Capoeira Angola (FICA), pesquisa temas ligados à capoeira, sobretudo relacionados ao berimbau. E destacou o papel do saber musical, como elemento de narrativa histórica:

Na verdade isso depende muito de cada grupo, de cada mestre, e de como a importância que ele dá para a musicalidade da capoeira, sabe? Então se eu for falar capoeiristicamente, eu vejo que a música é super importante, né. Ela tem uma importância fundamental até para o próprio desenvolvimento da mentalidade do capoeirista. Eu acho que a música conta muita história, conta fantasia da capoeira, conta as lendas da capoeira, né. As músicas têm uma certa, vamos colocar assim, uma certa moral que ela te passa, entendeu? Então isso para mim é fundamental, né. Escutar uma história do Riachão, escutar uma história do Besouro, né.

Para esse mestre, a música tem ainda "uma importância, principalmente para o iniciante de capoeira, fundamental, no sentido de mostrar para ele que a capoeira vai muito além da movimentação corporal"(MESTRE CoBRINHA).

Os papéis atribuídos às musicalidades pelos participantes dessa roda contribuem para conhecermos os significados que esses saberes adquirem na capoeira, tais como: 1) o fato de a capoeira praticada hoje ser fundamentalmente caracterizada pela presença da música, como disse Frede; 2) a ideia de que as músicas influenciam no desempenho das funções, de o jogo ter mais harmonia e o "cara se soltar mais", de fazer com que os capoeiristas sejam alegres, parecendo formar uma família, como disseram Frede, Mestre Neco e o Mestre Raimundo, respectivamente; 3) a compreensão de que a capoeira vai além da movimentação corporal, como disse Mestre Cobrinha; 4) a possibilidade de colocar todos numa mesma consciência, criando um contexto de comunicação ou um elo com o cosmo, como disseram Mestre Cafuné, Mestre China e Mestre Môa; 5) a história da capoeira ou função narrativa, como disseram Frede e Mestre Cobrinha etc. 
A continuidade dessa roda de depoimentos pode confirmar, como será visto, as influências deixadas por alguns mestres nas práticas musicais $\mathrm{da} /$ na capoeira. Também demonstra as diferentes visões e significados que os mestres de capoeira expressam, hoje, sobre as musicalidades das rodas de capoeira.

\section{As MUSICALIDADES DAS RODAS DE CAPOEIRA: UM SABER/PODER}

Nesta altura, é possível verificar, por um lado, que a música favorece as aprendizagens coletivas, nos cenários de capoeira, ligadas à animação da roda, à narrativa histórica e à interação das consciências, conforme visto acima. Por outro, parecem emergir aspectos que dão vazão à hipótese de as musicalidades das rodas de capoeira configurarem relações de saber/poder; a partir de estratificações e disputas, conforme a continuidade da explicitação e a análise dos dados.

A configuração de hierarquias relacionadas às musicalidades diz respeito à necessidade de os(as) educadores de capoeira terem o mínimo de domínio deste saber. Pelo exposto, pode-se perceber que as musicalidades são saberes fundamentais e estruturantes da atuação desses educadores(as) como será visto, a preponderância destes saberes foi motivo para que esses agentes questionassem uns aos outros. Daí saber como os interlocutores veem a necessidade de os(as) educadores(as) de capoeira possuírem saberes musicais foi outra questão recorrente nas entrevistas.

Por exemplo, ao perguntar a Mestre Neco se o educador de capoeira deveria saber música para coordenar o ensino de capoeira, ele opinou:

Olha, para o cara ter condição de tomar conta de um trabalho sério, porque eu fui para o colégio em 1970 e já fui cantando, tocando e jogando mesmo bem capoeira, em 70. [...] E eles têm que aprender a tocar, cantar e jogar. E tem vez que eu pego lá eu digo: "Olha, cada um vai cantar uma ladainha corrida." Hoje eu canto, acho que é vinte e seis ladainhas, vinte e seis, porque tem mestre de capoeira que não sabe cantar uma ladainha. (MESTRE NECO)

Mestre Neco deu a entender que ensinar alunos(as) a tocarem e a cantarem, em conjunto, é uma das formas de promover o acesso a esses saberes. Argumenta trabalhar desta forma: "Porque tem mestre aí que não deixa nem o aluno pegar no berimbau dele". E afirmou que em suas aulas há espaço reservado para o ensino da música:

Tem, porque se você chegar lá você vai ver três, quatro pandeiros. Aí você vai ficar admirado que na lógica é dois, mas se eu botar dois quase ninguém vai aprender, né. Aí eu boto quatro, tem vez que eu boto dois atabaques, 
porque quanto mais eles forem tocando, tocando, tocando, vão aprendendo. (Mestre Neco)

Os próprios mestres aqui estudados iriam travar jogos de poder em torno dos saberes musicais da capoeira. A declaração de Mestre Bimba sobre os berimbaus dos "angola", pode ser vista como polêmica - ao dizer que eram de madeira verde, pintada, para turistas e, no entanto, os seus é que eram os berimbaus autênticos.

Vou explicar pra vocês os berimbau verdadeiro: madeira tirada do mato, com quinze dias, depois de seca, a madeira chamada biriba; entonce, se bota um pedaço de couro; metesse o arame e depois passa uma pinça de verniz; é a única coisa. Não é como os berimbau dos angola, que eles tira a madeira verde, pinta e vende aos turista, por um bom berimbau. No entanto, o berimbau autêntico, verdadeiro são esses, são esses que eu faço. (Moura, 1968; grifos meus)

Os entrevistados têm diferentes pontos de vista sobre as aparentes disputas ou relações de saber/poder, na capoeira. Para falar sobre tal situação, convido à roda o Mestre Nenel, da Capoeira Regional, responsável pela Fundação Mestre Bimba, em Salvador. Ele procurou esclarecer o sentido das declarações de Mestre Bimba, dizendo:

Veja bem, as pessoas que enxergam coisa negativa nisso, são pessoas vazias, né, de sabedoria, a verdade é essa. E eu já ouvi comentários a respeito: "Ah, o Mestre Bimba esculhambava os angoleiros." Meu pai nunca esculhambou angoleiro, sempre respeitou, né. A colocação que ele fez, se você pesquisar, ele não falou nada que não seja verdade. O que ele falou era que, na época, hoje talvez mais não, mas na época que ele falou, que deu aquele depoimento, foi o quê? Sessenta e..., nem me lembro mais que ano que foi que ele fez aquele depoimento. $O$ que ele fala ali é o seguinte: que os berimbaus autênticos era esse, no caso, que ele fazia. (Mestre Nenel)

E acrescentou que Mestre Bimba conservaria uma forma de feitio do berimbau, originada na África:

E realmente são porque ele ainda conserva a mesma forma primitiva da África, né? Mas o mais..., a parte mais importante disso, é que ele fala, que não é como os angola, se referindo porque na época que se vendia, aqui no Mercado Modelo, realmente era qualquer madeira, que o cara tirava madeira verde lá, raspava e pintava e vendia pelo bom berimbau. Então, onde é que está a mentira dele aí? Então, na verdade ele não desrespeitou ninguém. Ele estava dizendo que o berimbau dele era autêntico, que até hoje eu continuo fazendo a mesma coisa que ele faz, eu não pego madeira verde de jeito nenhum, eu descasco e deixo aí 15 dias, 20 dias secando. Mas eu falei para você: eu tenho berimbau aqui que fica dois anos amansando. (Mestre Nenel) 
O Mestre Nenel observou que, à época, as críticas de Mestre Bimba foram reconhecidas por angoleiros como sendo válidas, e até hoje esses aspectos, ligados à comercialização do berimbau, estão presentes nos cenários de capoeira:

E tem mais uma coisa, e eu não vou dizer nomes, mas eu conheço, pelo menos, três pessoas, né, que são da Capoeira Angola e que falam: "Não, realmente seu pai tinha razão." E eu tenho um amigo aqui em baixo, que também é da Capoeira Angola, que vende, um dos maiores vendedores que tem de berimbau atualmente na Bahia é ele, e ele fala assim, para a turma: "Rapaz e eu vou pegar berimbau bom para vender para turista para os caras botar na parede lá. Os caras nem sabem tocar! Eu vou aí pintar bonitinho e jogar para lá!" E ele está certo. Então, se outra pessoa chega assim: “Ah, meu berimbau não é como dessa pessoa que vende lá para os turistas. Meu berimbau é autêntico." Não está falando nada de irreal. Então muitas pessoas tentam achar alguma coisa no Bimba para poder tentar criticar erroneamente. Né, a crítica construtiva é legal, mas... E não vai achar nunca. Quer queira, quer não, a música na capoeira, a própria capoeira no contexto geral, está hoje onde está, tem que agradecer ao Bimba mesmo, foi ele que sociabilizou a capoeira, foi ele que colocou..., seduziu a sociedade. (Mestre Nenel)

Da mesma forma, no campo das musicalidades, Mestre Pastinha foi fortemente questionado por Mestre Waldemar da Paixão.

Quando Aberrê faleceu, de repente, de colapso, tava cheio de mestre de capoeira, eu perguntei pra ele um dia: 'Pastinha, que é que você vai tirar pra mestre aí?' [Aí, se referindo à Gengibirra]. Ele disse: 'Waldemar, aqui não tem mestre. $O$ mestre vai ser todo mundo.' E eu disse que ele tinha que tirar um mestre bom para botar na capoeira. Eu já tava mestrando capoeira na Liberdade. Sempre ele me convidava para passar lá. Ele disse 'Tem muito mestre, mas eu vou te falar a verdade: o mestre vou ser eu mesmo'. Ele era presidente da capoeira. Prova é que ele não tocava berimbau, não tocava. Ele era pintor de parede. Ele faleceu e deixou alunos melhores do que ele. (ABREu, 2003, p. 53)

O pesquisador Frede vê essas declarações como meio-atritos: “É a mesma coisa de hoje. Só que aquilo se dava num..., se dava numa forma, em outro sistema, entendeu. Então eu acho que aquelas coisas ali, na verdade aqueles meio-atritos, não são nem grandes atritos; porque na verdade depois eles se encontravam e tal". Para ele, este clima de disputa faz parte do ambiente da capoeira e é ele que o alimenta.

Então esse ambiente, ele é um ambiente que é o tempo todo questionado; capoeira, o tempo todo o cara está disputando. Esse clima de disputa, ele 
é extremamente saudável, ele alimenta, não é. Quando eles falavam essas coisas, o Pastinha se defendia, também. Você tem o Pastinha se defendendo e comendo o cacete também [risos] em cima dos caras, não é; botando pra lenhá, explicando porque ele é grande e não tem como se derrubar a grandeza dele, não é - ele fala isso.

Frede afirma que essas declarações de Mestre Waldemar surgem num momento em que Mestre Pastinha e Mestre Bimba estão tendo destaque no cenário da capoeira: “Ele [Mestre Waldemar] já está em 35, você já tem Angola e Regional, está entendendo. As coisas já bem delineadas. Ou se não estão bem delineadas [risos], pelo menos politicamente já estão conflitadas, está entendendo. E ele então - como é que diz-já vendo essa disputa"(ABREu, 2003).

Mestre Cobrinha não viu polêmica nas declarações de Mestre Waldemar, dizendo:"Não. O que o Mestre Waldemar declara não é que Mestre Pastinha com relação à música, ele fala com relação ao Mestre Pastinha tocar instrumentos, sabe?" E comentou que a ideia de que Mestre Pastinha não saberia tocar "instrumento" vem criando polêmica; mas direcionou a discussão para o ensino da música:

É, sabe, o cara não saber tocar um instrumento, sabe? Agora essa coisa do Mestre Pastinha não saber tocar instrumento é uma coisa que vem criando uma polêmica muito grande, né. Assim, um dia mesmo teve pela internet as pessoas estavam fazendo essa coisa. Eu acho que Mestre Pastinha sabia tocar berimbau, como declaração mesmo do próprio Mestre Moraes e outras pessoas, né, que... Eu acho que as pessoas esperavam que ele como mestre de capoeira tocasse muito mais, entendeu? (MESTRE CoBRA MANSA; grifos meus)

Assim as visões e práticas de musicalidades dos mestres historiados, Bimba, Canjiquinha, Pastinha e Waldemar da Paixão, exerceram influências nas musicalidades, dinamizadas nos cenários de capoeira, o que pode ser atestado nos diálogos com os entrevistados. Isso faz com que esses mestres do passado ocupem posições de destaque no universo da capoeira, ainda hoje, no que diz respeito à constituição desse campo cultural, permeado por uma intensa riqueza e diversidade dessas musicalidades.

\section{CANTO DE DESPEDIDA: CONSIDERAÇÕES FINAIS}

O canto de despedida, executado ao final das rodas de capoeira, representa o momento de fazer um balanço "dos jogos jogados" e observar o que fica em aberto para novos jogos em outras rodas de capoeira.

A possibilidade das musicalidades desempenharem diferentes papéis nas rodas de capoeira faz com que este saber adquira relevância para 
se pensar a atuação e os processos de conhecimento de seus educadores. Esta dimensão é ligada às práticas educativas musicais, na capoeira, dinamizadas a partir de execução coletiva de cantos de pergunta e resposta; execução de instrumentos musicais, como berimbau, pandeiro, atabaque; acompanhamento rítmico, por meio de palmas, típico de práticas culturais afro-brasileiras, como batuques, samba de roda, umbanda, candomblé.

Estas práticas de educação musical também são vistas na medida em que os mestres e professores de capoeira desenvolvem estratégias de ensino da música, tanto nas aulas, como nas rodas de capoeira. Nas primeiras, o mestre ou professor exerce o papel de "educador musical" quando emprega estratégias para que os educandos aprendam a tocar instrumentos usuais da capoeira. Isso inclui conhecimentos históricos, rítmicos, canto de pergunta e resposta, entre outros, que caracterizam a dinamização de saberes musicais. Esses processos de educação musical também são vistos na medida em que seus agentes compartilham experiências estéticas em torno da música (BEYER, 2001), visto ser essa uma das características das práticas culturais, como atividades que movem um grupo ou comunidade numa determinada direção orientada previamente sob um ponto de vista estético, político ou ideológico (CоElHo, 1999).

Essa dimensão esteve ligada à história de mestres de capoeira, que viveram na Bahia, entre 1890 e 1994. Historiar a atuação de mestres de capoeira, como Bimba, Canjiquinha, Pastinha e Waldemar, permite argumentar que eles influenciaram as práticas musicais da capoeira, através das suas visões de musicalidades. Esta historização também caracterizou disputas que ocorrem no universo da capoeira, que envolvem não só a defesa de uma visão de musicalidade, mas o questionamento da visão e, portanto, da legitimidade do outro.

Nos meados do século XX, essas visões de musicalidades começam a se espalhar por todo Brasil, em razão dos movimentos migratórios de capoeiristas, em parte acarretados pela intensificação do capitalismo (ARAúso, 2008). Da mesma forma, o processo visto na tese da internacionalização da capoeira (FALCÃo, 2004) contribui para tal difusão. Evidentemente, as influências das visões de musicalidades provenientes da Bahia não anulam outras contribuições, advindas, por exemplo, de redutos de capoeiristas, como as cidades de Rio de Janeiro, São Paulo, Florianópolis, Curitiba, Recife, Brasília, Porto Alegre, entre outras, que mereceriam capítulos à parte na investigação desta prática cultural.

Assim, a ideia de rodas de capoeira permitiu, por um lado, fazer alusão às possibilidades de aprendizagem das musicalidades nas rodas da capoeira, 
confirmadas pelos depoimentos dos entrevistados. Por outro, as rodas de capoeira são representação espaço-temporal de conflitos e disputas em torno das musicalidades. Nas rodas de capoeira, as aprendizagens musicais podem ser reafirmadas e dinamizadas; mas essas aprendizagens também podem ser tensionadas por jogos de forças, o que acontece sutilmente, por exemplo, quando um instrumento musical é negado por um participante a outro de menor graduação.

A análise das musicalidades da capoeira aponta para

o capital simbólico - outro nome da distinção - [que] não é outra coisa senão o capital, qualquer que seja a sua espécie, quando percebido por um agente dotado de categorias de percepção resultantes da incorporação da estrutura da sua distribuição, quer dizer, quando conhecido e reconhecido como algo óbvio. (BouRdieu, 2003, p. 145)

O capital simbólico pode ser manifesto nas posições que os agentes do campo da capoeira ocupam (que correspondem a uma hierarquia de títulos, como mestres, professores etc.).

Seria necessário aprofundar a análise de um possível habitus capoeirístico, em torno da discussão das musicalidades. Sobre esse conceito afirma Bourdieu (2000, p. 36-37):

A mediação entre essa posição no espaço social e as práticas, preferências, é o que chamo de habitus, ou seja, uma disposição geral diante do mundo, que pode ser relativamente independente da posição ocupada no momento considerado, por ser rastro de toda uma trajetória passada, que está no princípio de tomadas sistemáticas de posição.

As noções de campo e capital simbólico (BouRdieu, 1996, 2000; 2003) contribuem para a análise das musicalidades, em sua dimensão educativa, como saberes centrais da atuação dos professores de capoeira. Os dados analisados contribuem para o pensamento de que as musicalidades, na capoeira, são parte da caracterização de um campo de poder, dinamizado a partir de regras de sentido, rituais, categorias de percepção, mas, sobretudo, por meio de jogos de força que contribuem para o estabelecimento das posições que os agentes ocupam neste espaço social.

THE MUSICALITY OF CAPOEIRA: ANALYSIS OF A FIELD OF KNOWLEDGE/POWER (?)

ABSTRACT: This paper analyzes the roles of the musicality of capoeira. It uses the idea of field in its analysis of the contradiction between the intercultural educational potential of the musicality in/of capoeira and the possibility of its becoming a motive 
for dispute between its agents. As the thread of the argumentative plot, it highlights the idea of capoeira circles as an allegory for the method presented. The data used are aspects of the stories of capoeira masters who lived in Salvador, Bahia, between 1890 and 1994; and interviews conducted over three months of fieldwork in the city. The study produced contributions for research on the teaching-learning process of the musicality and the building of teachers'knowledge in non-formal spaces, understood as fields of knowledge and power.

Key words: Capoeira. Musicality. Field. Educators.

LAS MUSICALIDADES DE LAS RODAS DE LA CAPOEIRA: INVESTIGACIÓN DE UN CAMPO DE SABER/PODER(?)

Resumen: En este texto se discuten los papeles de las musicalidades de la capoeira. Se recurre a la noción de campo en el análisis de la contradicción entre el potencial educativo intercultural de las musicalidades en la capoeira y la posibilidad de constituirse en objetos de disputas entre sus agentes. Se destaca como hilo conductor de la trama argumentativa, la idea de rondas de capoeira como alegoría para el método expositivo. Se toman como datos los aspectos de las historias de maestros de capoeira que vivieron en Salvador, capital del estado de Bahía, entre 1890 y 1994; y entrevistas realizadas durante tres meses de trabajo de campo en aquella ciudad. El trabajo resultó en contribuciones concernientes a la investigación de los procesos de enseñanza-aprendizaje de las musicalidades y la constitución de los saberes de educadores en espacios no formales, entendidos como campos de saber y de poder. Palabras claves: Capoeira. Musicalidades. Campo. Educadores.

\section{NOTAS}

1. Valente Vilela, canção de caráter narrativo, típica das rodas de capoeira e atribuída a Mestre Waldemar da Paixão.

2. A visão de educação formal diz respeito à caracterização dos processos educativos dinamizados nos espaços escolares formalmente institucionalizados, enquanto as práticas educativas não formais estão ligadas às aprendizagens dinamizadas no cotidiano; por exemplo, nos movimentos sociais e nas práticas culturais (Fleuri, 2001); (Freire, 1987; 1996); Simson e outros (2001). Sobre processos não formais de educação musical, este trabalho toma como referência Souza (2001) e Beyer (2001).

3. O referido trabalho de campo foi realizado com apoio do CNPq, na forma de bolsa de estudos para realização de estágio de doutorado-sanduíche, junto à Faculdade Educação da Universidade Federal da Bahia. Este trabalho foi desenvolvido no âmbito de pesquisa de doutorado, que resultou em tese, defendida junto ao PPGE/CED/ UFSC, CORTE REAL (2006). 
4. Há indícios de que a literatura de cordel receba este nome por referência a um tipo semelhante encontrado em Portugal e pelo fato de os livros serem postos à venda em "cavalgando um barbante", conforme o esclarece Galvão (2001, p. 27), que pode ser consultada para maiores detalhes.

\section{REFERÊNCIAS}

ABIP, P. Capoeira Angola: cultura popular o jogo dos saberes na roda. Tese (Doutorado em Educação) - Faculdade de Educação da Universidade de Campinas, Campinas, São Paulo, 2004.

ABREU, F. O barracão do mestre Waldemar. Salvador: Zarabatana, 2003.

ALVARENGA, O. Música popular brasileira. Porto Alegre: Globo, 1950.

ANDREOLA, B. A. Freire, Fanon e Mounier: um exemplo de diálogo intercultural. Santa Maria: Atas do /l Fórum de Estudos: Leituras de Paulo Freire. PPGE/CE/UFSM. Disponível em: <http://www.ufsm.br>. Acesso em: 15 maio 2000.

ARAÚJO, B.C.L. A capoeira na sociedade do capital: a docência como mercadoria-chave na transformação da capoeira do século XX. Dissertação (Mestrado em Educação) - Centro de Ciências da Educação da Universidade Federal de Santa Catarina, Florianópolis, Santa Catarina, 2008.

BEYER, E. O formal e o informal na educação musical: o caso da educação infantil. In: Anais do IV Encontro regional da ABEM Sul, Educação musical hoje: múltiplos espaços, novas demandas profissionais. Santa Maria: UFSM, 2001. p. 45-52.

BIANCARDI, E. Raízes musicais da Bahia. Salvador: Omar G., 2000.

. Olelê maculelê. Brasília: Especial, 1989.

BOURDIEU, P. As regras das artes: gênese e estrutura do campo literário. São Paulo: Companhia das Letras, 1996.

. O campo econômico: a dimensão simbólica da dominação. LINS, D. (Org.). Campinas: Papirus, 2000.

. A miséria do mundo. 4. ed. Petrópolis: Vozes, 2001.

. O poder simbólico. Rio de Janeiro: Bertrand Brasil, 2003.

COELHO, T. Dicionário crítico de política cultural. São Paulo: Iluminuras, 1999.

CORTE REAL, M. P. As musicalidades das rodas de capoeira(s): diálogos interculturais, campo e atuação de educadores. Tese (Doutorado em Educação) - Centro de Ciências da Educação da Universidade Federal de Santa Catarina, Florianópolis, Santa Catarina, 2006.

FALCÃO, J. L. O jogo de capoeira em construção e a práxis capoeira. Tese (Doutorado em Educação) - Faculdade de Educação da Universidade Federal da Bahia, Salvador, Bahia, 2004. 
.Puxada de rede. Florianópolis: Mover/UFSC, Confraria Catarinense de Capoeira, 2005. (Mimeo.).

FLEURI, R. M. Educação popular e universidade: contradições e perspectivas emergentes nas experiências de extensão universitária em educação popular da Universidade Metodista de Piracicaba (1978-1987). Florianópolis: NUP/CED/UFSC, 2001.

FREIRE, P. Pedagogia do oprimido. 17. ed. São Paulo: Paz e Terra, 1987.

. Pedagogia da autonomia: saberes necessários à prática educativa. 12. ed. Rio de Janeiro: Paz e Terra, 1996.

LANDES, R. A cidade das mulheres. 2. ed. Rio de Janeiro: UFRJ, 2002.

GALVÃO, A. M. O. Cordel: leitores e ouvintes. Belo Horizonte: Autêntica, 2001.

Mestre Canjiquinha. Mestre Canjiquinha: a alegria da capoeira - módulo educativo 1. MOREIRA, A. (Coord.). Salvador: Fundação Cultural do Estado da Bahia, s.d.

PASTINHA, V. F. Capoeira Angola. 2. ed. Salvador: Escola Gráfica Nossa Senhora do Louredo, 1968.

PIRES, A. L. C. S. A capoeira na Bahia de Todos os Santos: um estudo sobre cultura e classes trabalhadoras (1890-1937). Palmas: Fundação Federal do Tocantins: NEAB/ Grafset, 2004.

OLIVEIRA, A. M. de. Berimbau: o arco musical da capoeira na Bahia. Revista do Instituto Geográfico e Histórico da Bahia. Salvador, v. 80, p. 225-264, 1956.

REGO, W. Capoeira Angola: ensaio sócio-etnográfico. Salvador: Itapuã, 1968.

REIS, L.V.S. O mundo de pernas para o ar: a capoeira no Brasil. São Paulo: Publisher, 1997.

SHAFFER, K. O berimbau-de-barriga e seus toques. Rio de Janeiro: FUNARTE, 1977.

SOUZA, J. O formal e o informal na educação musical no ensino médio. Anais do IV Encontro regional da ABEM Sul Educação musical hoje: múltiplos espaços, novas demandas profissionais. Santa Maria: UFSM, p. 38-44, 2001.

UCSAL. Revista memorias da Bahia. Salvador: UCSAL: 2003.

VIEIRA, L. R. O jogo de capoeira: cultura popular no Brasil. Rio de Janeiro: Sprint, 1995.

VON SIMSON, O. R. de M. et al. (Orgs.). Educação não formal: cenários da criação. Campinas: Unicamp, 2001.

AUDIO-VISUAIS:

MOURA, J. Dança de guerra. Salvador, 1968.

MESTRE BIMBA. Curso de capoeira regional. Salvador, 1997.

MESTRE CANQUINHA e MESTRE WALDEMAR. Capoeira. São Paulo: MCK, s.d. 
Márcio Penna Corte Real é doutor em Educação pela UFSC; mestre em Educação e licenciado em Educação Artística, habilitação em Música pela UFSM. Professor da disciplina de Arte e Educação da FE, e do Mestrado Interdisciplinar em Performances Culturais da EMAC, ambos na UFG.

E-mail:mpcortereal@yahoo.com.br 